\title{
Open Learning Experience Bingo
}

\author{
Nathan Angell \\ Hypothesis \\ Angela Gunder \\ Online Learning Consortium
}

\author{
Correspondence: \\ Nathan Angell \\ Hypothesis \\ Email: nate at xolotl.org
}

\begin{abstract}
Definitions of openness and open education abound, but with so many, how can we use them effectively to explore the openness of assignments, activities, classes, or programs? Open Learning Experience Bingo is a game that a group of collaborators have created to give people a way to surface and discuss the many different ways that educational experiences can "open" beyond traditional practices. Each bingo card includes boxes containing possible "ingredients" in a learning experience, and radiating from the center of each box, "dimensions" of openness along which an ingredient might be opened. You "play" bingo by reading or hearing about a learning experience and marking areas on the bingo card that you think the experience opens. The game incorporates broad concepts of openness and seeks not to measure the openness of learning experiences, but to identify and spark discussion about areas in which experiences are opening or might be opened further. As artifacts, completed bingo cards display a sort of "heat map" of openness that can be used to compare and contrast bingo evaluations of various learning experiences.
\end{abstract}

Keywords: activity, bibliography, bingo, collaboration, design, education, games, learning, OER, open, openness, pedagogy, practices, rubric, teaching 


\section{Introduction}

Open Learning Experience Bingo grew out of a virtual instructional design challenge during OLC Accelerate 2019 and is designed to offer a way for people to consider how learning experiences - like activities, assignments, modules, or courses - might be "opened" in various ways. For example, a learning experience might be opened by enabling wider access to more people, more agency for people involved, or more possibilities in its materials, tools, goals, outcomes, and/or design.

Previous works on open educational materials and practices often provide frameworks designed to categorize what counts as openness in education (see the collaborative bibliography developed as a part of this game). It is beyond our scope here to provide a review of the full literature defining "openness" in education. Rather than attempting to foreclose what counts as a singular, autonomous definition of "open," the game tries to include as many dimensions and interpretations of "openness" as possible and build in opportunities for additional interpretations to be added. One might say the game is open to more openness.

This game began its development as a rubric to evaluate the openness of educational activities. Many such rubrics to evaluate openness in education have been published (see examples), but in following the classic structure of rubrics, they mostly work to define greater or lesser degrees of openness. By moving from rubric to bingo format, this game moved from being a tool to measure openness to instead become a generative tool to identify where openness is happening and think about where it could be expanded. It also invites users to consider how openness is situated contextually and negotiated socially in educational activities based on the people, practices, and perspectives involved. The game format creates a space for dialogue to think more deeply about where openness sits, and how it is applied in ways that are meaningful to specific communities.

The game design is also itself open: There are open spaces for people to add other ingredients and/or dimensions of openness and the borders of the card are also left open in various places to suggest that the game's boundaries could be opened even more. People can continue to contribute to the game's evolution: they can join the wide group of open education practitioners who have collaborated on its design so far and have also started a living collaborative bibliography of resources related to open educational practices. The game is openly licensed via CC BY 4.0, and people can access easily modifiable bingo card files in multiple formats.

\section{Ingredients of Learning Experiences}

Boxes on the bingo card represent the ingredients of learning experiences: materials, activities, skills, tools, people, roles, places, times, goals, feedback, evaluation, recognition, and design. The simple version of the bingo card is just these ingredient boxes, where players consider the openness of a learning experience in relation to each box with the answer to a simple question: Does this experience open this box of ingredients? Some boxes are left open for players to add their own ingredients. 


\section{Figure 1}

Open Learning Experience Bingo Simplified 2.0

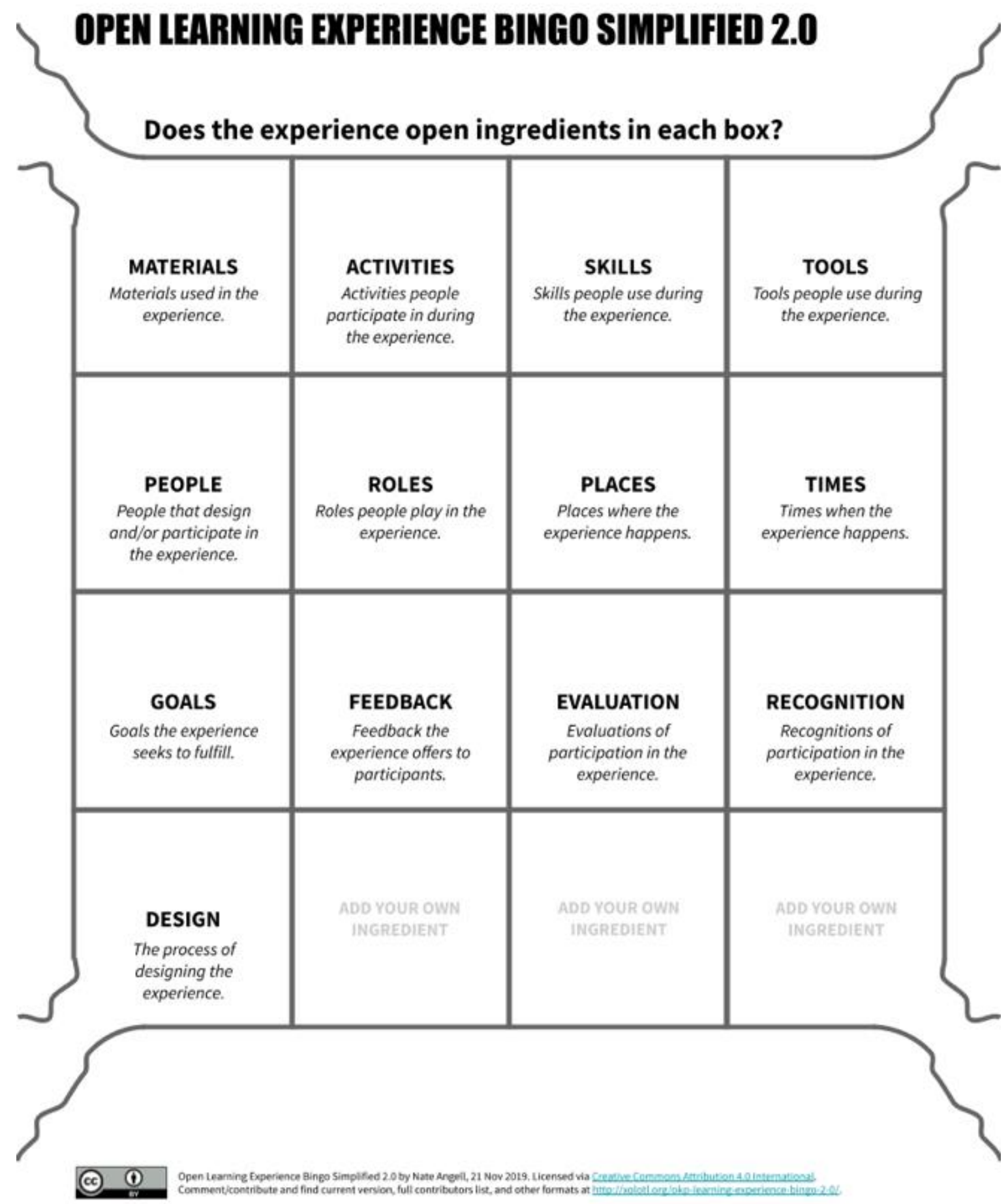

Note. An openness bingo card, showing boxes for ingredients: Materials, Activities, Skills, Tools, People, Roles, Places, Times, Goals, Feedback, Evaluation, Recognition, Design, and three empty boxes for players to add their own ingredients. Open Learning Experience Bingo Simplified 2.0 by Nate Angell Licensed via Creative Commons Attribution 4.0 International 


\section{Dimensions of Openness}

Beyond this basic question of whether any particular box IS being "opened" in a learning experience, there's the question of HOW it's being opened. The full version of the bingo card includes "dimensions of openness," radiating out from the center of each ingredient box like pie slices to avoid the idea of hierarchy. An ingredient might be expanding along one dimension and not another (eg, a skill in a learning experience might be developed but not reflected upon), but the bingo card does not seek to measure whether one dimension of openness is better or more important than another. Players are invited to add their own dimensions of openness starting with a pie slice purposely left open.

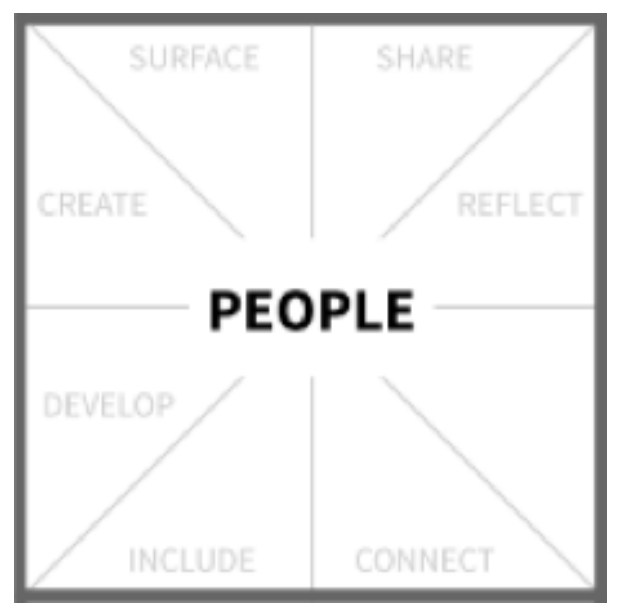

Note. Close up of the "People" ingredient box on an openness bingo card, showing dimensions: Connect, Create, Develop, Include, Reflect, Share, Surface, and an open space for players to add their own dimension.

Dimensions of openness include:

- Surface: Are ingredients surfaced in the experience (which we see as a prerequisite for their opening)? For example, a player might ask:

- Are the roles people play in the experience clearly articulated?

- Can we witness the recognition people receive by participating in the experience?

- Are the goals of the experience clearly stated?

- Share: Are ingredients shared with others? (Note: we are not building in any judgement here about how ingredients are shared (eg, with open licenses) as we believe the nuances of sharing are complex, depend on context, and sharing in any way can be an opening). For example, a player might ask:

- Are the materials or tools used and/or created in the experience made public?

- Are the materials or tools used and/or created in the experience openly licensed?

$\circ$ Is the design of the learning experience itself shared in ways that others can adopt/adapt/reuse it?

- Create: Do participants create/revise/remix ingredients? For example, a player might ask:

- Do participants change the places where the experience happens?

- Do participants create/remix/revise materials in the experience? 
- Are participants involved in creating the processes used to evaluate their work?

- Develop: Do participants develop ingredients over time? For example, a player might ask:

- Do participants change the roles they play in the experience?

- Do participants modify the tools they use in the experience?

- Does the experience provide participants with opportunities to modify the design of the experience itself?

- Reflect: Do participants reflect on ingredients during the experience? (Note: This is a meta-cognitive dimension.) For example, a player might ask:

- Does the experience enable participants to think about the roles they play in it?

- Do participants reflect on the goals of the experience, how they engaged in them, and/or how the goals might be different/better for themselves or others?

- Do participants have opportunities to reflect on evaluations they have given and/or received in the experience?

- Include: Do ingredients engage diverse people in the experience? For example, a player might ask:

- Are marginalized people engaged purposefully as a part of the experience?

- Do materials provide space for perspectives they do not already represent?

- Does the timing of the experience enable participation by people in other timezones?

- Connect: Do ingredients connect outward, increasing their audience, impact, lifespan, intertextuality, etc? For example, a player might ask:

- Do the materials created by participants have value for a wider audience outside the context of the experience?

- Might activities disseminated by participants fruitfully engage other people for some time outside the context of the experience itself?

- Do the goals of the experience connect to participants' other activities/goals beyond the experience?

The game is included in Robin DeRosa and Rajiv Jhangiani's Open Pedagogy Notebook, and you can find the record of its development and a growing collection of worked examples on $\underline{a}$ publicly available website.

\section{How to Play Openness Bingo}

Reflecting the openness of the bingo card itself, ways to play openness bingo are also left open, starting from common bingo gameplay in the USA: Whether you are playing with the simple version of the bingo card with just the ingredient boxes, or the full version including dimensions of openness, each player just marks the areas on their card where they find that a specific educational experience enables or generates openness.

In a basic example where a player is bingoing a specific educational experience, like a class: If anyone can participate in that class without cost, the player might mark the "people" ingredient as very open - coloring it in or marking with a game piece (not included). If the player is using the full bingo card with dimensions of openness and the class provides specific ways to include more diverse participants, the player might mark the "include" dimension in the "people" ingredient box. The player would then go on to consider the openness of the class related to each ingredient (and/or dimension) on their bingo card, marking areas where they identify openness. 

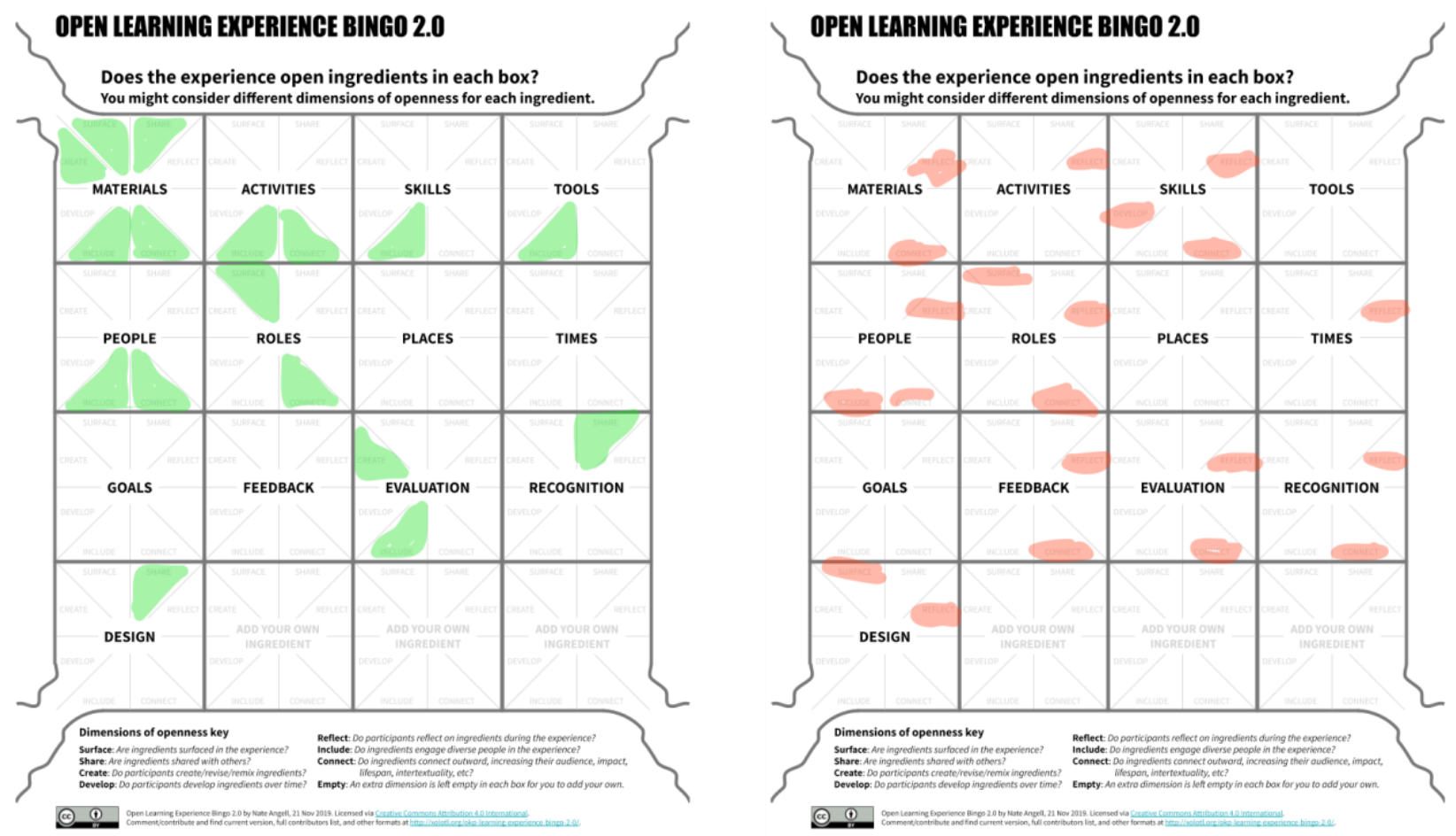

Note. Example Open Learning Experience bingo cards, showing how dimensions in ingredient boxes might be marked to identify openness in a specific learning experience. Explore the original bingo cards where the left card and the right card were marked.

People might play openness bingo in a variety of different ways: as an individual or group activity, synchronously at the same time and place or virtually at different times and places, as part of a formal review of educational practices or as an informal party game. For example:

An individual educator might prepare for an upcoming term by playing bingo by themselves, marking a bingo card for every class they teach as a way to explore and document how their courses and planned activities are already open, and/or might be opened more. As you can see in example bingo cards above, playing openness bingo with several experiences creates "heat maps" of openness that enable you to identify where openness is happening more or less in each experience or across them all. The card on the left shows a lot of openness in the "materials" ingredient and several ingredients where the "include" dimension shows openness. The card on the right shows many ingredients with openness in the "reflect" dimension. After playing bingo, one might see such patterns of openness or its lack by noticing how specific ingredients and/or dimensions are consistently marked - or not - across an entire collection of learning experiences.

A group of students might pause midway through a class to bingo their participation so far: In what ways have class activities been open? In what ways might the class be opened more as it continues or the next time it happens? Because each student is likely to identify and mark the openness of the class ingredients and dimensions differently, the class might review and discuss all the bingo cards after play, exploring different perspectives on openness and student experience. 
People might join a social gathering at a scholarly conference to bingo a collection of syllabi projected one-by-one to the whole crowd, marking off ingredients and dimensions of openness that they identify in each syllabus until someone creates a "bingo" and then explains to the other players how a particular syllabus demonstrates openness across a whole row, column or diagonal line of their card.

\section{Extending the Game}

With its open design, the game also demonstrates and encourages a kind of meta-openness: Every time the bingo is played, participants can discuss how playing the game helps (or hinders) exploring and understanding openness in education, and how the game itself might be improved or expanded. Being openly licensed itself, openness bingo also makes it easy for others to extend or modify the game. For example, Abbey Elder created a companion activity, Open Learning Experiences Fortune Teller Activity, that provides a creative way for bingo players to choose a dimension to focus on as they evaluate the openness of an ingredient in an educational experience. In creating and sharing openness bingo, our hope is that more people will share their uses, modifications, and extensions of the game so we can all expand both the openness of learning experiences, and how we think of openness in education.

\section{Author's Contributions}

Nathan Angell and Angela Gunder have collaborated on all the writing in this article, which describes the collaborative, openly-licensed work of a larger group of people referenced below under Acknowledgements.

\section{Open Researcher and Contributor Identifier (ORCID)}

Nathan Angell (iD https://orcid.org/0000-0002-5224-3384

Angela Gunder (iD https://orcid.org/0000-0003-4977-7737

\section{Acknowledgements}

The Open Learning Experience Bingo game and collaborative bibliography in this article were created collaboratively and openly licensed by Angela Gunder, Apurva Ashok, Christina Hendricks, Christina Riehman-Murphy, David Wiley, Greg McVerry, Heather Angell, Ken Bauer, Maha Bali, Monica Brown, Nate Angell, Paul Bond, Rajiv Jhangiani, Remi Kalir, Robin DeRosa, and Twyla Angell. A full record of the collaboration is available online.

\section{Ethics Statement}

Ethics review is not applicable.

\section{Conflict of Interest}

The authors do not declare any conflict of interest.

\section{Data Availability Statement}

This article is not based on any data, but Open Learning Experience Bingo game artifacts are available online, along with the collaborative bibliography also included below. 


\section{Collaborative Bibliography}

Adam, T., Allen, N., Amiel, T., Asino, T. I., Atenas, J., Bali, M., Barnes, N., Bourg, C., Bouterse, S., Caines, A., Campbell, L. M., Cangialosi, K., Collier, A. M., Cronin, C., Czerniewicz, L., DeRosa, R., Ensor, S., Friedrich, C., Gilliard, C., ... Watters, A. (2020). Open at the Margins: Critical Perspectives on Open Education. Rebus Community. https://press.rebus.community/openatthemargins/

Angell, N. (n.d.). Posts tagged "Learning Experience Bingo." Nate Angell. Retrieved December 1, 2021, from http://xolotl.org/tags/leb/

Angell, N. (2019a, December 1). OKP Learning Experience Bingo 2.0. http://xolotl.org/okplearning-experience-bingo-2-0/

Angell, N. (2019b, December 7). Open Learning Experience Bingo 2.0. Open Pedagogy Notebook. http://openpedagogy.org/assignment/open-learning-experience-bingo-2-0/

Angell, N. (2019c, December 7). Open Learning Experience Bingo: What Open Education Taught Me. Retrieved December 1, 2021, from http://xolotl.org/open-learning-bingowhat-open-education-taught-me/

Angell, N. (2019d, December 11). Open Learning Bingo: Zines as Open Pedagogy. Retrieved December 1, 2021, from http://xolotl.org/open-learning-bingo-zines-as-open-pedagogy/

Bali, M. (2017a, April 20). What is Open Pedagogy? \#YearOfOpen hangout April 24. Reflecting Allowed. https://blog.mahabali.me/whyopen/what-is-open-pedagogy-yearofopenhangout-april-24/

Bali, M. (2017b, April 21). Curation of Posts on Open Pedagogy \#YearOfOpen. Reflecting Allowed. https://blog.mahabali.me/whyopen/curation-of-posts-on-open-pedagogyyearofopen/

Bali, M. (2019, October 29). Openness in Whose Interest? \#OERizona \#OpenEd19. Reflecting Allowed: Maha Bali's Blog about Education. https://blog.mahabali.me/pedagogy/criticalpedagogy/openness-in-whose-interest-oerizona-opened19/

Baroud, F., Cox, G., Rao, A., Smith, P., \& Touze, S. (n.d.). What is Open Education? Year of Open. Retrieved December 2, 2019, from https://www.yearofopen.org/what-is-openeducation/

Bingo (American version). (2021). In Wikipedia. https://en.wikipedia.org/w/index.php?title=Bingo (American version)\&oldid=1058091083

Cape Town Open Education Declaration 10th Anniversary. (n.d.). Retrieved December 1, 2019, from https://www.capetowndeclaration.org/cpt10/

Cormier, D. (2019, March 24). Open Pedagogy - A three day seminar at Digital Pedagogy Lab. http://davecormier.com/edblog/2019/03/24/open-pedagogy-a-three-day-seminar-atdigital-pedagogy-lab/

Cronin, C. (2017). Openness and Praxis: Exploring the Use of Open Educational Practices in Higher Education. The International Review of Research in Open and Distributed Learning, 18(5). http://www.irrodl.org/index.php/irrodl/article/view/3096

DeRosa, R. (2017, April 24). Open Pedagogy: Quick Reflection for \#YearOfOpen. Actualham. http://robinderosa.net/uncategorized/1775/

DeRosa, R., \& Jhangiani, R. (2018, March 16). Open Pedagogy Notebook. Open Pedagogy Notebook. http://openpedagogy.org/open-pedagogy/

Elder, A. (n.d.). Open Learning Experiences “Fortune teller." Google Docs. Retrieved December 1,2021 , from https://docs.google.com/drawings/d/1ctBZle9wsolwJZ0MV3QY3CCeTxYRAVSXF82EU 93P3go/edit?usp=sharing\&usp=embed facebook

Hodgkinson-Williams, C. A., \& Trotter, H. (2018). A Social Justice Framework for Understanding Open Educational Resources and Practices in the Global South. Journal of Learning for Development - JL4D, 5(3). http://il4d.org/index.php/ej|4d/article/view/312 
Inamorato dos Santos, A., Punie, Y., \& Castaño-Muñoz, J. (2016). Opening up Education: A Support Framework for Higher Education Institutions (RC Science for Policy Report, p. 78) [Text]. Publications Office of the European Union. https://ec.europa.eu/jrc/en/publication/eur-scientific-and-technical-researchreports/opening-education-support-framework-higher-education-institutions

Lambert, S. R. (2018). Changing our (Dis)Course: A Distinctive Social Justice Aligned Definition of Open Education. Journal of Learning for Development - JL4D, 5(3). https://il4d.org/index.php/ejl4d/article/view/290

McVerry, G. (2019, November 1). Draft Framework for Effective Teaching and Higher Ed. INTERTEXTrEVOLUTION. https://jgregorymcverry.com/frameworkforeffectivehighered

Oblinger, D. G. (2012). Game Changers: Education and Information Technologies. EDUCAUSE. https://www.educause.edu/research-and-publications/books/gamechangers-education-and-information-technologies

OLC Quality Scorecard-Improve the Quality of Online Learning \& Teaching. (n.d.). OLC. Retrieved November 25, 2019, from https://onlinelearningconsortium.org/consult/olcquality-scorecard-blended-learning-programs/

Online Learning Consortium. (2019a, November). Attend OLC Accelerate 2019. OLC. https://onlinelearningconsortium.org/attend-2019/accelerate/

Online Learning Consortium. (2019b, November 19). OLC Accelerate_OLC Live! Virtual Hub. OLC. https://onlinelearningconsortium.org/attend-2019/accelerate/virtual-hub/olc-live/

OSCQR. (n.d.). Retrieved November 25, 2019, from https://oscar.org/

QM Rubrics \& Standards / Quality Matters. (n.d.). Retrieved November 25, 2019, from https://www.qualitymatters.org/qa-resources/rubric-standards

Schuwer, R., Bali, M., Green, A. G., Jhangiani, R., Ross, H. M., \& Ritter, D. (n.d.). What is Open Pedagogy? Year of Open. Retrieved December 2, 2019, from https://www.yearofopen.org/april-open-perspective-what-is-open-pedagogy/

The Cape Town Open Education Declaration. (n.d.). Retrieved December 1, 2019, from https://www.capetowndeclaration.org/read-the-declaration

University of Illinois at Urbana-Champaign Scholarly Communications and Publishing. (2021, October 3). LibGuides: Open Educational Resources (OER): Evaluate OER. https://guides. library. illinois.edu/c.php?g=246992\&p=1645967

Wiley, D. (2013, October 21). What is Open Pedagogy? Iterating toward Openness. https://opencontent.org/blog/archives/2975

Wiley, D., \& Hilton, J. (2018). View of Defining OER-Enabled Pedagogy. International Review of Research in Open and Distributed Learning, 19(4). http://www.irrodl.org/index.php/irrodl/article/view/3601/4724 